\title{
EDUCAÇÃO A DISTÂNCIA E ENSINO DE TEATRO: CONFLUENCIAS NO ENSINO MÉDIO
}

\author{
Jailson Araújo Carvalho \\ jailsoncarvalho1@gmail.com
}

\section{Mesa temática 3. Mediação Teatral e Metodologias de Ensino}

\begin{abstract}
Resumo:
O presente estudo teve por objetivo investigar a tecnologia como alternativa para o processo de experiência estética teatral no Ensino Médio. Com o evidente avanço nas novas tecnologias, é possível perceber que o processo de ensino e aprendizagem não acompanha tal evolução. Assim, constatam-se nos estudantes de então um vasto uso das tecnologias contemporâneas, porém, a escola não entende o quanto a questão pode ser uma ferramenta transformadora para seu processo de ensino e aprendizagem. Neste ínterim, buscou-se: 1) discutir a utilização dos dispositivos móveis como suporte para a utilização do Moodle em sala de aula; 2) analisar o modo pelo qual os estudantes se relacionam com a tecnologia, por meio dos dispositivos móveis, nas aulas de Artes; 3) escrever como se dá a interação entre os estudantes durante as experimentações teatral a partir da utilização da tecnologia; e, 4) examinar as elaborações estéticas estruturadas e seus resultados. Como viés metodológico fez-se uso de estudo de caso com abordagem qualitativa. A unidade de caso observada foi o Centro Educacional 104 da Região Administrativa do Recanto das Emas, Distrito Federal. Como resultados, foi possível elaborar três produtos estéticos, a saber: Performances Teatrais Digitais, Stop Motion e Fotografias Cênicas.
\end{abstract}

Palavras-chave: Teatro. Tecnologia. Educação.

\begin{abstract}
:
The present study aimed to investigate technology as an alternative to the theatrical aesthetic experience process in High School. With the evident advance in the new technologies, it is possible to perceive that the process of teaching and learning does not follow this evolution. Thus, in the students of the time, a vast use of contemporary technologies is verified, however, the school does not understand how much the question can be a transforming tool for its teaching and learning process. In the meantime, we sought to: 1) discuss the use of mobile devices as a support for the use of Moodle in the classroom; 2) to analyze the way in which students relate to technology, through mobile devices, in Arts classes; 3) write how it gives the interaction between the students during the theatrical trials from the use of technology; and, 4) to examine the structured aesthetic elaborations and their results. As a methodological bias, a case study with a qualitative approach was used. The case unit observed was Educational Center 104 of the Recanto das Emas Administrative Region, Federal District. As a result, it was possible to elaborate three aesthetic products, namely: Digital Theatrical Performances, Stop Motion and Scenic Photographs.
\end{abstract}

Keywords: Theater. Technology. Education.

Atualmente, a tecnologia é uma ferramenta muito importante para a comunicação humana. Com o surgimento da internet, podemos interligar vários computadores, 
celulares, tablets, independentemente da posição geográfica no planeta. A tecnologia precisa adentrar o espaço educacional como uma ferramenta de apoio para o processo de ensino e de aprendizado. Ela começou a ser um meio de comunicação entre professores e estudantes, “já que permite juntar a escrita, a fala e a proximidade da imagem a um custo barato, com rapidez, flexibilidade e interação até há pouco tempo impossíveis" (MORAN, 1997).

$\mathrm{Na}$ escola onde trabalho, o Centro Educacional 104 do Recanto das Emas/DF (CEd 104), percebemos alguns problemas com nossos estudantes. Muitos utilizam o celular de forma descontrolada, mesmo isso podendo ser algo agregador ao seu desenvolvimento intelectual. Para Ausubel (1963, p. 58), “a aprendizagem significativa é o mecanismo humano, por excelência, para adquirir e armazenar a vasta quantidade de ideias e informações representadas em qualquer campo de conhecimento". Para que este tipo de aprendizagem aconteça, são necessárias duas condições, que nos fazem refletir sobre os meios e os caminhos para se buscar o desenvolvimento intelectual, de forma que isso aconteça com significação.

Delimitamos como sujeitos envolvidos para esta pesquisa estudantes de duas turmas do terceiro ano do ensino médio do CEd 104 do turno matutino. Definimos como objetivo geral da pesquisa analisar a utilização da performance e do celular como ferramentas de reflexão com estes estudantes. E, como objetivos específicos: identificar como a utilização da performance influencia, de forma positiva, no processo de reflexão dos estudantes sobre a criação cênica; analisar a utilização do celular nas aulas de Artes. Além disso, tiramos proveito do mundo virtual para ampliar as possibilidades da pesquisa. Os estudantes de hoje já nascem no mundo digital, porém não são todos os que conseguem utilizar a tecnologia para ajudá-los no processo de ensino e de aprendizagem significativa. Alguns passam a maior parte do tempo enviando mensagens no WhatsApp, curtindo fotos no Instagran, compartilhando vídeos e fotos no Facebook e no Youtube.

A tecnologia influenciou para a mudança na trajetória de vários aspectos da sociedade (econômico, social, intelectual entre outros). Ela ocasionou uma ruptura no modelo metodológico da prática educacional, o que exigiu várias mudanças no planejamento diário dos professores. 
A pesquisa mostrou que, de forma positiva, a performance pode ser uma ferramenta de muita importância para o processo de ensino e de aprendizagem com estudantes do Ensino Médio no Centro Educacional 104 do Recanto das Emas/DF, pois ela fez com que cada discente olhasse um pouco para sua vida e como eles a conduziam. Ela consegue provocar inquietações e questionamentos, a ponto de mudar o pensamento e a direção de certas escolhas. Isto porque a "Performance mostrou-se interessada em expor as possibilidades de um corpo verdadeiro, por meio de sua realidade no mundo, de sua construção cultural”' (CUNHA, 2006, p. 31).

As aulas de Artes provocaram reflexões nos estudantes durante todo o semestre letivo, a partir da construção de um personagem que difere da sua realidade ou que é idêntica a ela. Em vários casos, o processo de composição da cena para a criação da performance despertou um olhar mais sensível sobre a realidade que estamos inseridos ao redor da escola e como isso afeta diretamente nossas vidas. E pudemos perceber que a grande maioria, inclusive aqueles que demonstraram total desinteresse pela disciplina, estão mais sensíveis e voltados para as questões artísticas, pois a participação dos estudantes nas atividades propostas nas aulas de Teatro foi aumentando a cada dia. Vários discentes, que no início do semestre se mostraram desinteressados e raramente participavam das aulas práticas, mudaram sua postura e começaram a cobrar as vivências cênicas. Em termos quantitativos, suas notas nas avaliações formais (provas) de Artes melhoraram muito.

\section{Referências}

AUSUBEL, David Paul. The psychology of meaningful verbal learning. New York, Grune and Stratton, 1963

CUNHA, Fernanda Pereira da. E-Arte/Educação: educação digital crítica. São Paulo: Annablume; Brasília: CAPES, 2012

MORAN, José Manuel. Como utilizar a Internet na escola. 1997. Disponível em <http://www.scielo.br/scielo.php?pid=s010019651997000200006\&script=sci_arttext $>$.

Acesso em: 20.abr.2018. 